\title{
The effect of goal proximity on acquisition and extinction of a five part response chain
}

\author{
JAMES L. BRUNING, PAUL W. BECKER AND ROBIN C. TUCKER ${ }^{1}$
}

OHIO UNIVERSITY

\begin{abstract}
The present study considered the effect of goal proximity on the rate of responding to each of five wheels in a response chain. Eighteen male, albino rats were used as Ss. The results indicated: (1) during the acquisition phase, response strength tended to increase as the Ss approached the goal, (2) the effect of nonreward was to initially increase response rate at the point farthest from the goal and to reduce it near the goal.
\end{abstract}

\section{Introduetion}

While the concept of response chaining has been discussed theoretically in relation to various types of instrumental learning situations (Spence, 1956), a review of the literature (Kelleher \& Gollub, 1962) indicates that most researchers have been concerned with manipulation of reinforcement schedules. Those studies designed specifically to examine response chaining have either required only that the $S$ respond several times to the same stimulus (Arnold, 1947; Weiss, 1961), or did not permit measurement of response strength to each unit (Corke, 1964).

The present experiment will consider two factors. First, the effect of goal proximity on the performance of Ss who must turn five different wheels in sequence will be investigated. Second, and of greater interest, will be consideration of the effect of non-reinforcement to determine which part of the five part response chain extinguishes most rapidly.

\section{Method}

Subjects: Eighteen male, albino rats, 160-190 days old were used as Ss and were maintained on a $23 \mathrm{hr}$. water deprivation schedule for the duration of the experiment.

Apparatus: The apparatus was a modified Skinner Box, 22-1/2 in long, 10 in wide, and $8-1 / 2$ in high. The sides and top were painted flat black, the front was clear Plexiglas. The opening for the water dipper and the five identical wheels were spaced $1-1 / 2$ in apart along the back wall of the box. Each wheel was made of two Plexiglas end plates, $2-3 / 4$ in in diameter. These were separated by 10 stainless steel spokes, 1-1/2 in long, placed equidistantly around the perimeter of the end plates.

Directly above each of the wheels was a small light which served as a cue to direct the $S$ to the correct wheel in the sequence. Two micro-switches, located at the bottom-center of each wheel, made contact with the spokes as the wheel was turned. The spoke contacts were recorded on counters whenever a wheel was turned while the lights above the wheels and the dipper mechanism operated only if the response sequence was performed correctly.

\section{Procedure}

Initial Shaping: The Ss had to be pre-trained to insure that they learned the five part chain. Initial training was begun on the wheel closest to the dipper (wheel No. 1) followed by a gradual lengthening of the chain until it included all five wheels.

Acquisition: At the beginning of each trial the light above wheel No. 5 (farthest from the dipper) was turned on. When $S$ rotated this wheel, the light turned off and the light above wheel No. 4 switched on automatically and stayed on until $\mathrm{S}$ turned that wheel. This continued until $\mathrm{S}$ had turned all five wheels in sequence, working from right to left. When the wheel closest to the dipper was turned, the dipper mechanism was activated and delivered $.01 \mathrm{cc}$ of water to the S. After $2.5 \mathrm{sec}$. the dipper retracted, the light above wheel No. 5 switched on and $\mathrm{S}$ could again perform the sequence to obtain another reinforcement. All Ss were given the same treatment during the acquisition phase. Training was continued until asymptotic performance was reached (15, 7-min. trials).

Extinction: The Ss were randomly divided into the following three experimental groups: (1) Primary On-No Cue (P-NC) This group continued to receive primary reinforcement, but the cue lights were switched off. (2) No Primary-Cue On (NP-C) The dipper was switched off so that no primary reinforcement was given, but the cue lights were left operable. (3) No Primary-No Cue (NP-NC) Both the dipper and the cue lights were switched off.

Nine extinction trials, $7 \mathrm{~min}$. duration each, were given each of the Ss. In all of the experimental groups, the number of sequences completed and also the number of times each wheel was turned were recorded.

\section{Results and Diseussion}

For purposes of statistical analysis and graphical representation, the data were grouped into blocks of three trials.

Acquisition: The Ss showed considerable variation of response strength in relation to the proximity of the goal. Except for a slightly heightened level of responding to wheel No. 5, the general trend was for response strength to increase as $S$ approached the goal, followed by a terminal decrement just as the goal was reached (See Fig. 1). This trend is very similar to the goal gradient speeds noued by Hull (1934) in a straight alley, and by Weiss (1961) in a moditied 


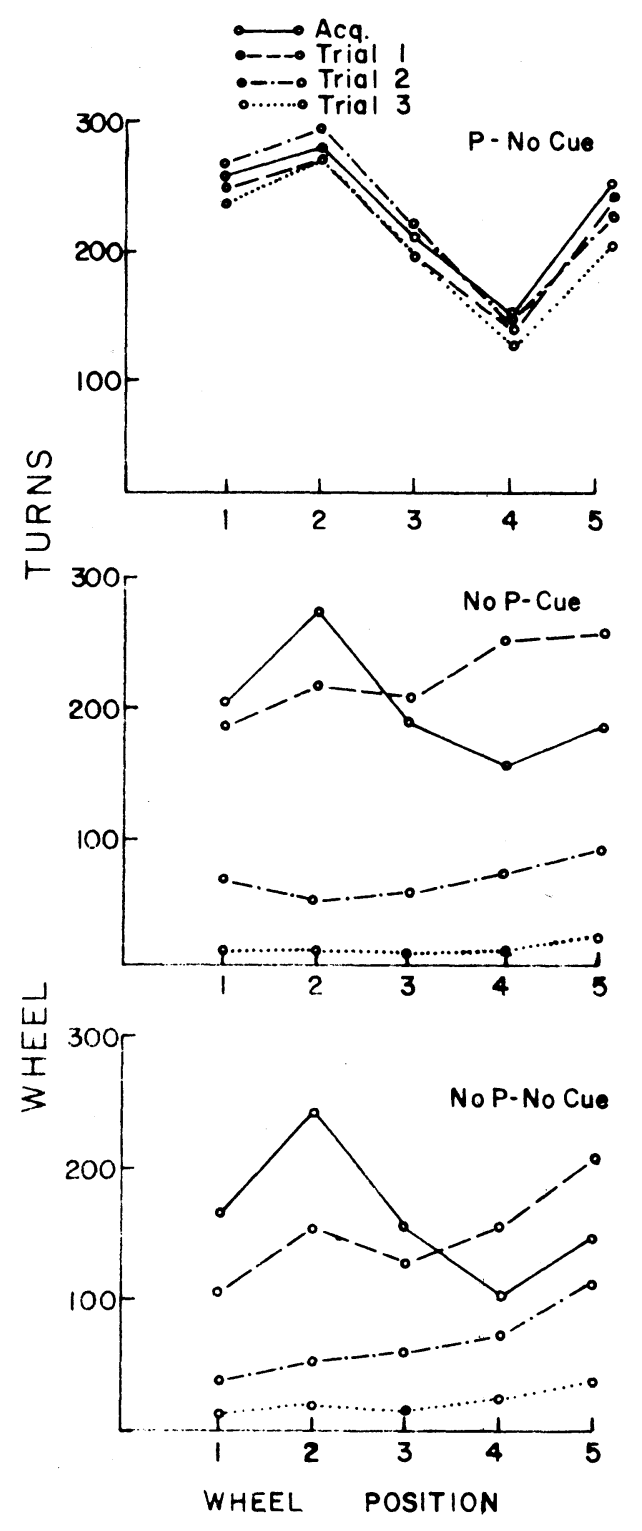

Fig. 1. Rate of wheel turning during extinction in relation to terminal acquisition performance level.

Skinner Box. Statistical analysis of this gradient effect indicated that it was significant beyond the .005 level $(F=4.99, d f=4 / 68)$.

Extinction: All three groups showed a decline in the number of sequences completed during the extinction trials $(F=57.19, d f=3 / 45)$. However, the rates of decline varied considerably. As would be expected, removal of only the cue lights (P-NC group) resulted in a relatively small decline, while removal of both primary reinforcement and the cue lights (NP-NC group) caused the most rapid extinction of the response chain.
Figure 1 presents the terminal acquisition level of each group and the subsequent changes in rate of wheel turning which occurred during the extinction period. From this figure it can be seen that the P-NC group showed little change while the performance of the NP-C and the NP-NC groups varied considerably.

The analysis of variance was computed to include the last block of xcquisition trials and tested for the effects of experimental groups, wheel position, and trials. This analysis indicated that the effects of experimental groups $(F=6.05, d f=2 / 15, p<.025)$, wheel position $(F=2.85, \mathrm{df}=4 / 60, \mathrm{p}<.05)$, trials $(\mathrm{F}=2.92$, $\mathrm{df}=3 / 45, \mathrm{p}<.05)$, trials by groups $(F=6.83, \mathrm{df}=6 / 45$, $\mathrm{p}<.001)$, and trials by wheel position $(\mathrm{F}=1.99$, $\mathrm{df}=$ $12 / 180, p<.05$ ) were all significant.

Of particular interest are the performance curves of the NP-C and the NP-NC groups on the first block of extinction trials. In both instances the effect of withdrawal of reward was to initially heighten the rate of responding to the wheel farthest from the goal and concomitantly, to lower performance near the goal. To test this shift in rate of turning the various wheels, an additional analysis was computed to compare performance on the last block of acquisition trials with that on the first block of extinction trials. This analysis showed that the trials by wheels interaction was significant for the NP-NC group $(F=4.22, d f=4 / 20, p<.025)$ and that it fell just short of significance for the NP-C group $(F=2.34, \mathrm{df}=4 / 20, .05<\mathrm{p}<.10)$. No change was noted in the P-NC group $(\mathrm{F}<1, \mathrm{df}=4 / 20)$.

While it appears that frustration raised drive and thus elicited the temporarily heightened rate of wheel turning, it cannot be determined from the present data whether this frustration generalized spatially from the goal area to the more distant parts of the chain (competing responses may have depressed performance near the goal), or, whether it generalized temporally and served as an internal stimulus and energizer of the wheel responses which occurred just following nonreward (most Ss went immediately to the beginning of the chain).

\section{Referenees}

Arnold, W. J. Simple reaction chains and their integration. J. comp. physiol. Psychol., 1947, 40, 349-363.

Corke, Patricia P. Complex behavior in "old" and "young" rats. Psychol. Rep., 1964, 15, 371-376.

Hull, C. L. The rat's speed of locomotion gradient in the approach to food. J. comp. Psychol., 1934, 17, 393-422.

Kelleher, R. T., \& Gollub, L. R. A review of positive conditioned reinforcement. J. exp. Anal. Behav., 1962, 5, 543-597.

Spence, K. W. Behavior theory and conditioning. New Haven: Yale University Press. 1956.

Spence, K. W. Behavior theory and learning. Englewood Cliffs: Prentice Hall, 1960.

Weiss, R. F. Response speed, amplitude, and resistance to extinction as joint functions of work and length of behavior chain. J. exp. Psychol., 1961, 61, 245-256.

\section{Note}

1. The authors acknowledge the technical assistance offered by Larry D. Daniels for construction of the wheels. 